\title{
Designing Port Services Via Fuzzy Quality Function Deployment
}

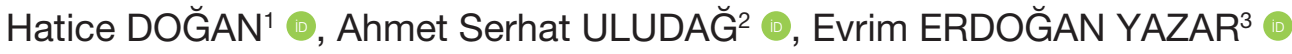

\begin{abstract}
The objective of this study is to develop a proposal for developing port services that can improve the service quality by accurately satisfying the customer requirements. In this study, a four-stage process was identified. In the first stage, data envelopment analysis (DEA) was used for measuring the efficiency of the container terminals. In the second stage, the requirements of the port customers were identified, and confirmatory factor analysis was applied for satisfying these requirements. Further, in the third stage, the consistency of the binary comparison matrices which consist of customer requirements was evaluated using the analytic hierarchy process (AHP). In the final stage, the fuzzy analytic hierarchy process (FAHP) and fuzzy quality function deployment (FQFD) were jointly used for designing the port services. According to results, the resources requirement is considered to the most important criterion among the main criteria to improve the service quality of the port. Further, FQFD was used for designing of P1 port's service. FQFD was concluded that the quality of the equipment, facilities, and technological infrastructure have to be improved for increasing the service quality of P1 port.
\end{abstract}

Keywords: Fuzzy Analytic Hierarchy Process, Fuzzy Quality Function Deployment, Confirmatory Factor Analysis, Port Service Design, Data Envelopment Analysis

JEL Classification Codes: M11, M39, N74

\section{INTRODUCTION}

The ports that form the backbone of maritime transport and their efficiency are considered the main factors that affect the performance of maritime transport. The ports that do not contain any docks, warehouses, and/or storage spaces that are suitable for different cargo and vessel types have no and/or poor connection to other forms of transportation, have technologically outdated equipment, fail to employ skilled labor, are inaccurately designed, or are not professionally managed are obstacles in obtaining favorable results in maritime transport. In the current competitive business environment, port operators must optimally use their scare resources and, simultaneously, adopt a professional, innovative, and proactive management approach for achieving their targets and objectives (Tahar and Hussain, 2000). This entails the design and presentation of the port services and all areas related port services in a manner that focuses not only on the port efficiency but also on customers (the port services should be responsive to the customer requirements) as well as the improvements.

However, this study focuses on the design of port services in accordance with the customer requirements. At this time, the following basic questions have to be answered: What are the customers' expectations from a port? How can these expectations be identified? How can the services be designed or improved to satisfy these expectations? This study searches for the answers to such questions. Further, this study intends to come up with a proposal for designing and developing port services that are capable of satisfying the customer requirements using Fuzzy Quality Function Deployment (FQFD). Subsequently, an existing questionnaire was

\footnotetext{
${ }^{1}$ Assistant Prof., Giresun University Vocational School of Social Sciences, Giresun, Turkey, hatice.dogan@giresun.edu.tr,

${ }^{2}$ Assistant Prof., Ondokuz Mayis University, Faculty of Economics and Administrative Sciences, International Trade and Logistics Department, Samsun, Turkey, serhat.uludag@omu.edu.tr

${ }^{3}$ Assistant Prof., Ondokuz Mayis University, Faculty of Economics and Administrative Sciences, Business Administration Department, Samsun, Turkey, evrim.erdogan@omu.edu.tr
} 
used to identify the expectations of the customers, and confirmatory factor analysis (CFA) was applied to this questionnaire. The questionnaire was finalized after this analysis was completed, and the revised questionnaire was used for determining the importance ratings and weights of customer expectations using the Fuzzy Analytic Hierarchy Process (FAHP). The efficient operation of a port was the key consideration for determining the port at which this study could be conducted and its rivals. Further, data envelopment analysis (DEA) was used for performing the efficiency analysis, and the efficient and inefficient ports were identified. One of the inefficient ports was selected for conducting this study. After these stages, the basic steps of FQFD were performed, and a service design proposal was obtained for the selected port.

The following sections in this study address the literature review, the basic issues related to the concept of port, data and used methodology, analysis and findings, and conclusions.

\section{LITERATURE REVIEW}

In this study, an extensive literature search was carried out to build up a strong theoretical background and to identify method and/or methods. Firstly, studies focused on port services design in the literature has been investigated in order to build up a strong theoretical background of this study. In line with this purpose, studies related to the subject have been researched th- rough keywords by using online databases and internet search engines, especially EBSCO Discovery Service (On 22.05.2020). The distribution of the studies reached as a result of the search by keyword groups is shown in Figure 1. Due to the limitation of the page, these studies could not be included in detail.

As can be seen in Figure 1, among these studies, it is seen that those who are related to "port", "transport" and "design" issues are more numerous than others. The topics and methods of the studies examined with the literature research have not been elaborated since they are not "directly related" to the subject of this study.

In addition to determining the gap regarding the design of port services, the literature research also allowed us to determine what kind of problems are sought and which methods are used in the studies related to ports. In this context, the majority of the studies proposed solutions various network design problems with the help of mathematical models. Another issue that was emphasized as much as the network design was the measurement of the emission caused by the ships and the ports as a whole, and the analysis of their impact on the environment. Moreover, the studies that examine the negative effects of maritime transport, ports and ships on the environment and coastline through chemical analyzes are also remarkable. The methods used in these studies mentioned in Figure 2 are grouped under general headings.

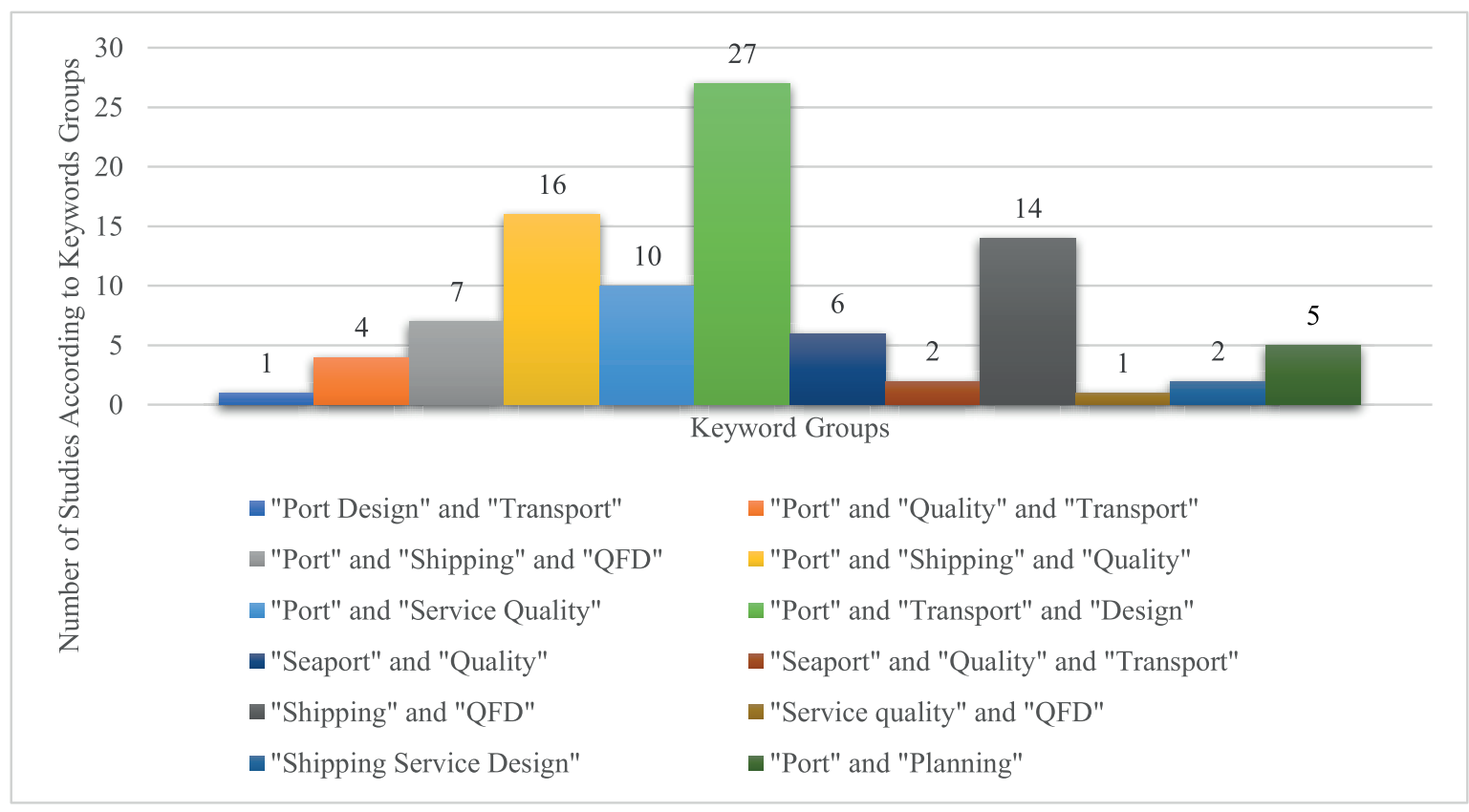

Figure 1: Distribution of studies reached through literature research by keywords 


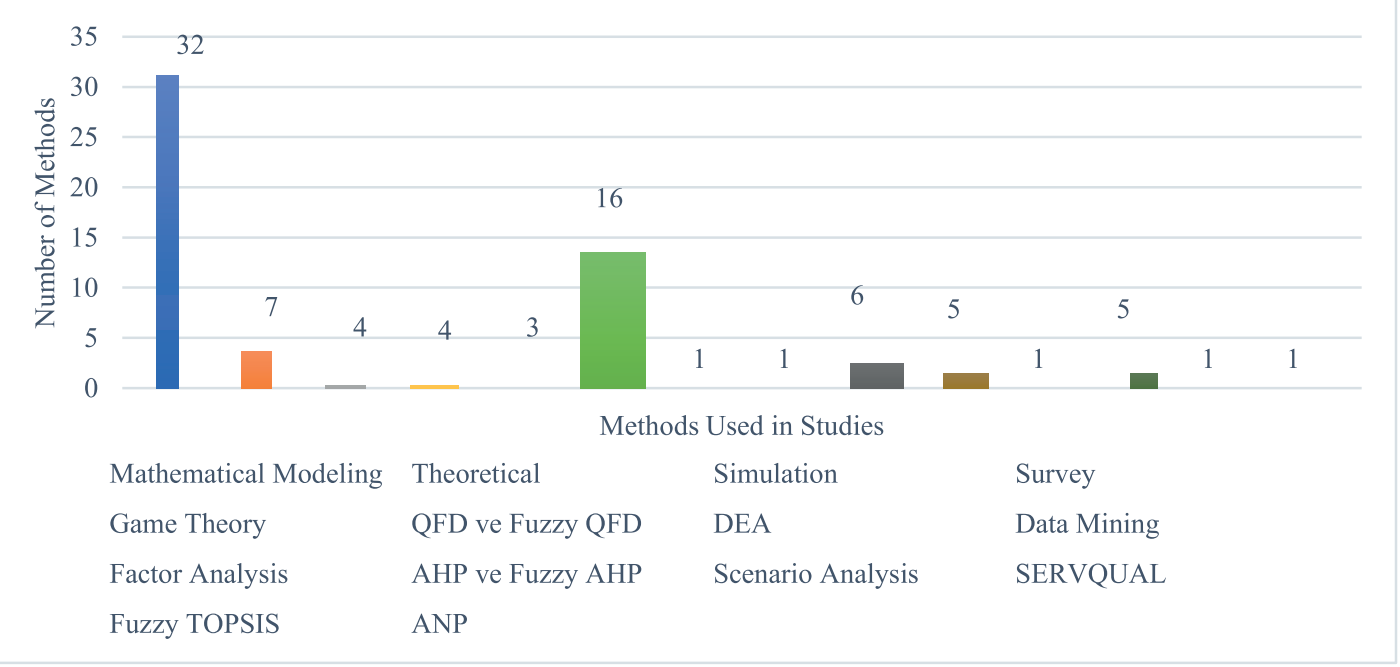

Figure 2: Distribution of the methods used in the studies reached by the literature research

As seen in the Figure 2; mathematical models, methods such as QFD and FQFD are used more than other techniques. Although methods such as QFD and FQFD seem to be the most preferred after mathematical models, the problems discussed in the studies in which these methods are used differ from the structure of the problem addressed and sought in this study.

In the current literature review, there are a limited number of studies focused on similar problem and methods used in the study. In this context; Ding (2009) used the FQFD method to define Kaohsiung Port's service delivery system (SDS) solutions from the perspective of customers and Duru et al. (2013) used the QFD method to determine the needs of both the customers and port operators. Hsu (2013) determined the service activities at the container terminals from a customer perspective by using the QFD method. Huang et al. (2015) also used the QFD method to improve the service quality of ship freight companies; Razik et al. (2015) used QFD and factor analysis together for improvement activities in dry cargo terminals from a customer perspective. In another study on service quality, Huang et al. (2019) used QFD and FAHP methods together to improve the service quality of large shipping companies.

In this study, unlike the studies examined with the literature research, port services were handled from a more holistic perspective. Different from current literature, the port services were evaluated from the perspective of customers for port authorities and it was aimed to present a proposal for the improvement of the services. Since the studies related service quality improvements at ports from consumer perspective are limited in number in the literature.
While there are studies that have investigated the product and service design using the FQFD, only a few studies have investigated the usage of quality function deployment (QFD) and/or FQFD for the design of port services; further, no study has been conducted in Turkey as of the date of the present study. In this context, this study will contribute to the literature related to study's subject in terms of its scope and methodology and encourage further studies.

\section{BASIC ISSUES RELATED TO THE CONCEPT OF PORT}

Ports include structures comprising several sections that can be referred to as terminals (Mangan et al., 2008) and perform the following five basic functions: serve as shelter for vessels; maintain, repair, and construct vessels; possess suitable infrastructure for handling, stowing, storing, and checking the loading operations; possess a suitable environment for the expansion of industry and commerce; and ensure the effectiveness of the transportation operations by connecting different transportation points (Branch, 1986). Based on these functions, the ports may be classified as state, municipal, private, and autonomous ports (Baird, 1995). However, the ports can also be classified as first, second, third (UNCTAD, 1992) and fourth generation according to the scope of the services which they offer (Esmer and Cetin, 2016).

The differentiation of ports in terms of their capacities and the services that they offer makes it difficult to develop a standard approach that is applicable to every port with respect to the measurement of the efficiency and service design. The factors that affect the performance and efficiency of a port include its 
geographic location, the availability of transportation modes, its technological infrastructure, its potential for expansion, the automation systems, its work load, the duration of cargo's stay in the port, its storage spaces and the manner in which these spaces are used, the number and adequacy of the handling equipment, its operation times, the capabilities of the crane operators, the professional qualifications and the training levels of the staff, the occurrence of natural disasters, and the persons or organizations related to the port.

Currently, to ensure efficient operation of ports, to ensure customer satisfaction, and to become larger than their rivals, the port operators must recognize the changes in the customer requirements of global trade and take the lead in undergoing transformation before being forced to transform or to become innovative. The increase in global trade volume and cargo traffic, changes in customer expectations, introduction of heavy tonnage ships, technological advancements, and increased competition (TURKLIM, 2010); the competition rules, taxation systems, working conditions, security services, and regulations concerning customs and environmental protection (World Bank, 2007); the climate change, rising sea levels, storms, and natural disasters; (Becker et al., 2011) and several other factors make transformation inevitable for port operators.

\section{RESEARCH AND METHODOLOGY}

The objective of this study is to make a proposal for facilitating the improvement of the services that are provided at a port in accordance with the customer requirements. In this context, the first problem that should be solved is to identify the port at which the study has to be conducted. The efficiency score obtained using DEA was considered an evaluation criterion for selecting the port, a literature review on ports has been performed, and the input and output variables that can be used for performing efficiency analysis have been identified. The port having the lowest efficiency score in the analysis was selected for conducting this study. For the service design work to be conducted on the selected port, FQFD was used because it allowed the customers to be indirectly included in the design and the service production process. Subsequently, the AMOS 20 software package was employed to conduct CFA for verifying the validity and reliability of the service quality scale used to determine the customer requirements in FQFD. Further, to determine the importance rating of the customer requirements, the FAHP method was used, and a design proposal was created for the selected port by performing FQFD.

The research model has been presented in Figure 3 for a clear presentation of the aforementioned stages.

\subsection{Data Collection}

The data required for performing the efficiency analysis in the first stage of the application were collected from the Ministry of Transport, Maritime Affairs, and Communications and the websites of the 14 designated ports. DEA was performed using the data from 2014 because the accessible and reliable data on the ports originated in that year. The data that were required for determining the customer requirements were collected using the questionnaire forms. While preparing these questionnaire forms, a previously developed scale was used for measuring the service quality of the port operators. To verify the validity and reliability of this scale, 400 questionnaire forms were administered to port customers, and 337 valid questionnaire forms were collected. FAHP was employed for determining the importance rating of the customer requirements. This constitutes the first stage of FQFD. To obtain the data that were required at this stage, the questionnaire forms, which were prepared according to the hierarchy of goals and the main and sub-criteria, were given to 119 port customers by contacting them in person or via phone or e-mail, and the forms were taken back using the same method. Among the 93 questionnaire forms that were returned, 64 were observed to be usable. The data required for the creation of the planning matrix in the second stage of FQFD were obtained by handing over the questionnaire forms to 320 port customers by contacting them in person or via phone or e-mail, receiving 292 usable questionnaire forms in return. Further, a quality team comprising seven people who were experts in port services was formed, and the technical requirements of the ports were identified based on their opinions. To measure the degree of relation between the identified technical requirements and customer requirements, a relation matrix was created by consulting the quality team. Further, 16 experts who worked in the ports and who were knowledgeable about the port evaluated the questionnaire forms that were designed to determine the importance rating of technical requirements and to identify the target values. In the final stage, a correlation matrix was created to measure the relations among various technical requirements. 

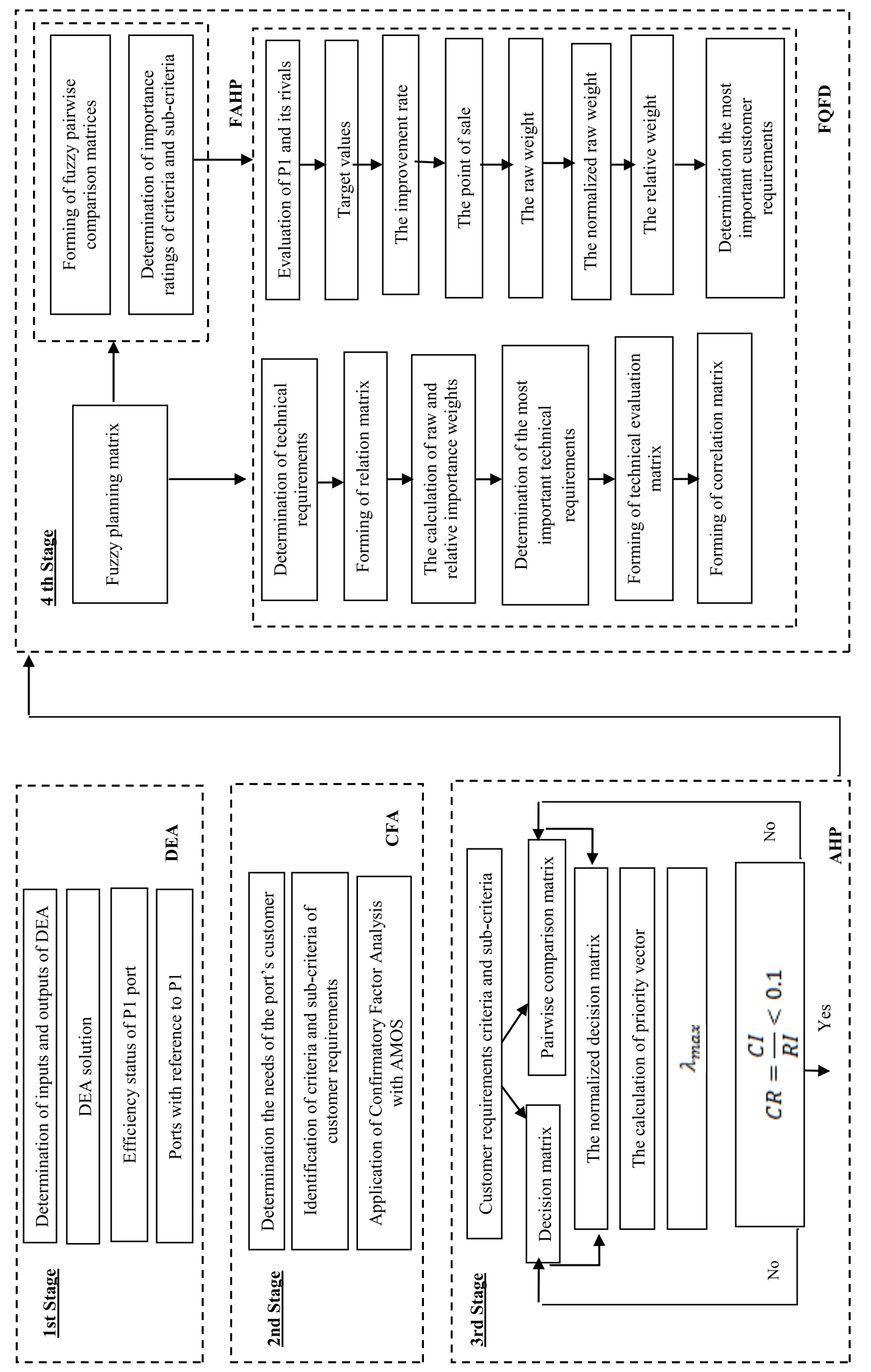

Figure 3: Model research 


\subsection{Research Methods}

This section is devoted to the descriptions of the DEA, CFA, fuzzy logic, FAHP, and FQFD methods that have been used in the application.

\subsubsection{Data envelopment analysis}

DEA is a data-driven analysis that is used for measuring the effectiveness of the decision-making units (DMUs) that convert multiple inputs into multiple outputs (Cooper et al., 2004). The DEA models are typically grouped into radial and non-radial models. The most commonly used non-radial DEA models are the additive model, slacks-based measure, hybrid measure, and Russell measure. However, the radial DEA models are categorized into constant returns to scale (CRS) and variable returns to scale (VRS). Based on the assumption of CRS, the CCR (Charnes-Cooper-Rhodes) model is used; further, based on the assumption of VRS, the BCC model is used; CCR and BBC models can be solved as being input- and output-oriented (Cooper et al., 2007). The objective of the input-oriented DEA models is to use the minimum input for obtaining a particular output, whereas the objective of the output-oriented DEA models is to create the maximum output using a particular amount of input (Charnes et al., 1994).

The data envelopment analysis includes six stages such as the selection of DMUs, determination of inputs and outputs, identification of the appropriate DEA model, assignment of the reference set, calculation of the potential improvement rates for ineffective DMUs, and the assessment of the results. DMUs should have similar inputs and outputs because their selection affects the results of analysis. Further, the DMUs should perform similar activities to achieve similar targets, should operate under similar market conditions, (Golany and Roll, 1989) and should be in adequate numbers (Bakirci, 2006). In the literature, there are various recommendations that can be used for determining the number of DMUs. In this context, the number of DMUs should be greater than or equal to the product of the number of used inputs with the number of outputs greater than or equal to three times the sum of the numbers of inputs and outputs according to (Cooper et al. (2001), whereas it should be no less than the sum of the numbers of the inputs and outputs according to Bakirci (2006); From (Boussofiane et al., 1991); further, it should be at least twice the product of the numbers of inputs and outputs according to Dyson et al. (2001).

Because the number of input and output variables that should be used in DEA is as important as the num- ber of DMUs, all the inputs and outputs that affect the effectiveness of the DMUs should be identified. If there are too many inputs and outputs, various methods should be used for determining the most important inputs and outputs and for reducing their number. The inputs are the resources that are used by the DMUs, and the outputs are the beneficial results of the activities of the DMUs. For obtaining meaningful results, a reasonable number of inputs and outputs should be included for performing the analysis. Because the increased number of inputs and outputs will increase the number of DMUs, it is important to accurately determine the inputs and outputs (Ramanathan, 2003). In DEA, the efficiency values of the DMUs will vary between 0 and 1 , where the DMUs whose efficiency score is 1 can be considered to be efficient while those having effectiveness scores of smaller than 1 can be considered to be inefficient (Weber, 1996).

\subsubsection{Confirmatory factor analysis}

Factor analysis is a type of multivariate analysis that allows the presentation of data in a meaningful and concise manner based on the relations among a group of variables (Nakip, 2013), and it is classified as explanatory and confirmatory. Exploratory factor analysis (EFC) is designed for cases in which the relations between the observed and latent variables are unknown or tentative (Byrne, 2010). However, CFA has been developed for verifying the validity of factor structures. In CFA, there are certain fit indices for verifying the consistency of the model. The most commonly used indices include the chi-square test statistics, root mean square error of approximation (RMSEA), standardized root mean square residual (SRMR), normed fit index (NFI), comparative fit index (CFI), goodness of fit index (GFI), and adjusted goodness of fit index (AGFI) (Schermelleh-Engel et al., 2003).

\subsubsection{Fuzzy logic and fuzzy numbers}

Fuzzy logic was initially introduced as a concept by L. A. Zadeh in his book, Fuzzy Sets, published in 1965. Fuzzy logic considers uncertainty, and it can be used to solve the problems without considering definite borders and values (Chamzini and Yakhchali, 2012). Further, Zadeh developed the theory of fuzzy sets because of the perception differences or uncertainties that are associated with human thought. In fuzzy logic, the linguistic variables are mathematically expressed (Ertugrul and Karakasoglu, 2008). Each element in a fuzzy set can take values ranging from 0 to 1 (Chan and Kumar, 2007). Further, the membership function 
for the fuzzy set $A$ can be expressed as $\mu_{\tilde{A}}(x) \rightarrow[0,1]$ . In literature, the triangular and trapezoidal fuzzy numbers are considered to be the most extensively used fuzzy numbers, and $\mu_{\widetilde{A}}=(l, m, u)$ is a triangular fuzzy number, where $l$ denotes the smallest possible value, $m$ denotes the possible value, and $u$ denotes the greatest possible value (Chang, 1996). The linguistic variables that are used in this study and the triangular fuzzy numbers that correspond to them are presented in Table 1 (Rao, 2008).

\subsubsection{Fuzzy analytic hierarchy process}

Fuzzy logic is suitable for solving real-life problems; this has led to the usage of fuzzy logic along with the traditional multiple-criteria decision-making methods. FAHP began to be used in the literature because of the aforementioned developments (Huang et al., 2008; Deng, 1999). In this study, the FAHP that was proposed by Chang (1996) was used, and its stages were shown below (Chang, 1996; Kahraman et al., 2004):

According to the order analysis conducted by Chang (1992), where $U=\left\{u_{1}, u_{2}, \ldots, u_{m}\right\}$ denotes the object set and $X=\left\{x_{1}, x_{2}, \ldots, x_{n}\right\}$ denotes the target set, $\left(g_{i}\right)$ is applied to each order analysis. Therefore, $m$ order analysis values are obtained for each object.

$$
M_{g i}^{j}: M_{g i}^{1}, M_{g i}^{2}, \ldots, M_{g i}^{m} \quad i=1,2, \ldots, n
$$

1st Stage: The calculation of the fuzzy synthetic order value for value $i$.

$$
S_{i}=\sum_{j=1}^{m} M_{g i}^{j} \otimes\left[\sum_{i=1}^{n} \sum_{j=1}^{m} M_{g i}^{j}\right]^{-1}
$$

Here, to calculate $\sum_{j=1}^{m} M_{g i}^{j}$ in Equation 2, the addition of the $m$ order analysis value is performed as follows:

$$
\sum_{j=1}^{m} M_{g i}^{j}=\left(\sum_{j=1}^{m} l_{j}, \sum_{j=1}^{m} m_{j}, \sum_{j=1}^{m} u_{j}\right)
$$

Further, to obtain the value of $\left[\sum_{i=1}^{n} \sum_{j=1}^{m} M_{g i}^{j}\right]$, the addition to the value $M_{g i}^{j}(j=1,2, \ldots, m)$ is performed.

$$
\left[\sum_{i=1}^{n} \sum_{j=1}^{m} M_{g i}^{j}\right]=\left(\sum_{i=1}^{n} l_{i}, \sum_{i=1}^{n} m_{i}, \sum_{i=1}^{n} u_{i}\right)
$$

Subsequently, the Equation 5 is obtained by taking inverse of Equation 4.

$$
\left[\sum_{i=1}^{n} \sum_{j=1}^{m} M_{g i}^{j}\right]^{-1}=\left(\frac{1}{\sum_{i=1}^{n} u_{i}}, \frac{1}{\sum_{i=1}^{n} m_{i}}, \frac{1}{\sum_{i=1}^{n} l_{i}}\right)
$$

2nd Stage: The degree of likelihood for the state $M_{1}=\left(l_{1}, m_{1}, u_{1}\right) \geq M_{2}=\left(l_{2}, m_{2}, u_{2}\right)$ can be given

\begin{tabular}{|c|c|c|c|}
\hline \multicolumn{2}{|l|}{ AHP } & \multicolumn{2}{|c|}{ FAHP } \\
\hline Degree of Importance & Definition & Fuzzy Numbers & Corresponding Numbers \\
\hline 1 & Equally important & $(1,1,3)$ & $(1 / 3,1,1)$ \\
\hline 3 & Weakly important & $(1,3,5)$ & $(1 / 5,1 / 3,1)$ \\
\hline 5 & Essentially important & $(3,5,7)$ & $(1 / 7,1 / 5,1 / 3)$ \\
\hline 7 & Very strong important & $(5,7,9)$ & $(1 / 9,1 / 7,1 / 5)$ \\
\hline 9 & Absolutely important & $(7,9,9)$ & $(1 / 9,1 / 9,1 / 7)$ \\
\hline 2 & Intermediate values & $(1,2,3)$ & $(1 / 3,1 / 2,1)$ \\
\hline 4 & Intermediate values & $(3,4,5)$ & $(1 / 5,1 / 4,1 / 3)$ \\
\hline 6 & Intermediate values & $(5,6,7)$ & $(1 / 7,1 / 6,1 / 5)$ \\
\hline 8 & Intermediate values & $(7,8,9)$ & $(1 / 9,1 / 8,1 / 7)$ \\
\hline
\end{tabular}
as follows:

$$
V\left(M_{1} \geq M_{2}\right)=\sup _{x \geq y}\left[\min \left(\mu_{M_{1}}(x), \mu_{M_{2}}(y)\right)\right](6)
$$

In other words:

Table 1: Importance Scale in AHP and Its Fuzzy Corresponding 


$$
V\left(M_{2} \geq M_{1}\right)=\operatorname{hgt}\left(M_{1} \cap M_{2}\right)=\mu_{M_{1}}(d)=\left\{\begin{array}{cc}
1, & m_{2} \geq m_{1} \\
0, & l_{1} \geq u_{2} \\
\frac{l_{1-u_{2}}}{\left(m_{2}-u_{2}\right)-\left(m_{1}-l_{1}\right)}, & \text { other }
\end{array}\right\}
$$

Here, $d$ denotes the ordinate of the highest intersection point between the points $\mu_{M_{1}}$ and $\mu_{M_{2^{\prime}}}$ as depicted in Figure 4. To compare the values of $M_{1}$ and $M_{2}$, both the values of $V\left(M_{1} \geq M_{2}\right)$ and $V\left(M_{2} \geq M_{1}\right)$ should be known.

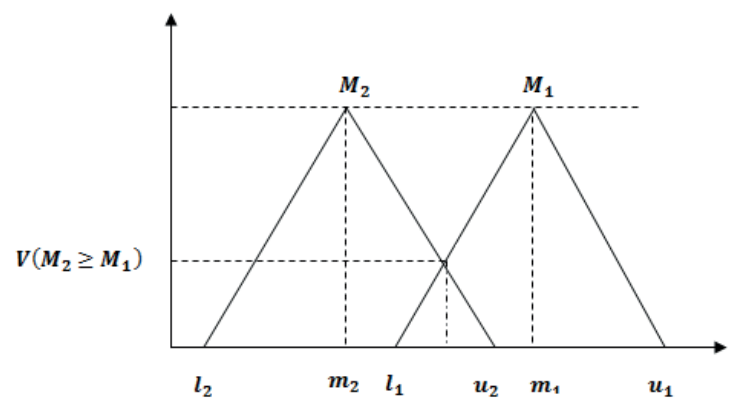

Figure 4: The Intersection Between of $M_{1}$ and $M_{2}$

3rd Stage: The likelihood degree that a convex fuzzy number will be $M_{i}(i=1,2, \ldots, k)$ greater than the convex fuzzy number $k$;

$$
\begin{aligned}
& \quad V\left(M \geq M_{1}, M_{2}, \ldots, M_{k}\right)=V\left[\left(M \geq M_{1}\right)\right. \text { and } \\
& \left.\left(M \geq M_{2}\right) \text { and } \ldots . \text { and }\left(M \geq M_{k}\right)\right] \\
& \min V\left(M \geq M_{i}\right), \quad i=1,2,3, \ldots, k
\end{aligned}
$$

$d^{\prime}\left(A_{i}\right)=\min V\left(S_{i} \geq S_{k}\right) \quad k=1,2,3, \ldots, n ; k \neq i$ for $W^{\prime}$.

In equation 8 and $9, W^{\prime}$ is weighting vector which consists of $n$ elements,

$$
W^{\prime}=\left(d^{\prime}\left(A_{1}\right), d^{\prime}\left(A_{2}\right), \ldots, d^{\prime}\left(A_{n}\right)\right)^{T}, A_{i}(i=1,2, \ldots, n)
$$

4th Stage: The calculation of the normalized weight vector $(W)$.

$$
W=\left(d\left(A_{1}\right), d\left(A_{2}\right), \ldots, d\left(A_{n}\right)\right)^{T}
$$

Here, the vector $W$ is not a fuzzy number. Defuzzification was also used in this study even though it is not one of the basic stages of AHP. While $\tilde{A}=(l, m, u)$ is a triangular fuzzy number, the formula presented in Equation (11) was used for performing the defuzzification (Bottani and Rizzi, 2006; Bevilacqua et al., 2012).

$$
A=\frac{l+2 m+u}{4}
$$

\subsubsection{Fuzzy quality function deployment}

The first stage of FQFD is the creation of the house of quality, similar to that in QFD. While creating the house of quality, the expert opinions are used for determining the customer requirements and the performances and technical requirements of the firm (organization, facility, port, product, service etc.) and its rivals. Because the expression of these opinions via linguistic variables creates uncertainty, fuzzy numbers are used to eliminate uncertainty and to reach definite conclusions (Buyukozkan et al., 2007; Khoo and Ho, 1996). FQFD, which can be used for designing new services or for improving the existing services, consists of several matrices. The resulting structure can be referred to as the house of quality because it resembles a house. In the house of quality, the horizontal matrices denote the customer requirements, whereas the vertical matrices denote the technical requirements.

The most important stage of the house of quality is the determination of the customer requirements that are located to the left of the house of quality. The columns of the planning matrix, which is located to the right of the house of quality, may change depending on the QFD teams. In general, the planning matrix contains the columns of the importance ratings of customer requirements, the status of the studied firms and its rivals, the target, the improvement rate, the point of sale, and the raw weight and relative weight scores (Costa et al., 2001; Jeong and Oh, 1998). Further, the importance ratings of the customer requirements are calculated by identifying the most important requirements; subsequently, the importance ratings are converted into numerical values; they are quite important because they are used in other stages of the house of quality. The column of the status of the firm and its rivals denotes the performance of the firm and its rivals in satisfying the customer requirements. The remaining columns in the planning matrix are the target column that denotes the achievable target values of the firm, the raw and relative weight column (Akbaba, 2005), and the point of sale column, where 
the customer requirements that may directly interfere with a sale are evaluated (Liu, 2009).

The technical requirements matrix depicts the manner in which the firm will satisfy the customer requirements. There should be at least one technical requirement corresponding to each customer requirement. Further, the suitable technical requirement can be identified by the QFD team using different methods. Because the number of technical requirements determines the number of columns in the matrix, the number of columns in the matrix increases along with the increasing number of such requirements, which further complicates the solution process and escalates the number of decisions that have to be made.

After the customer requirements and technical requirements are identified, each customer requirement is compared with the technical requirements to find the relation between them; further, the technical requirements are transferred to the production stage (Day, 1998). After the relation matrix is created, all lines of the matrix should be checked to remove the lines without any relation symbol or with only a weak relation symbol from the matrix.

The upper part of the house of quality is the roof or the correlation matrix, which denotes the relations among technical requirements. This matrix is important for observing the design process from which the bottleneck(s) may originate (Ficalora and Cohen, 2010). While the creation of the matrix of technical requirements in which the relation of priority or posteriority among technical requirements is described, the QFD team should take into consideration the technical requirements of both the firm and its rivals. After this stage, the targeted technical requirements for the firm as well as raw and relative importance weights should be determined (Han et al., 2001; Jeong and Oh, 1998).

\subsection{Determining The Port Through Data Envelopment Analysis}

As noted above, the first question that should be answered is the port in which the port service design will be performed. However, the distinct characteristics of ports complicate the quest for an answer to this question. In this context, we have investigated the similarities among the ports in Turkey. When the criterion of container handling was considered, we obtained a higher number of ports than what we obtained from the remaining criteria. Therefore, the port for the application was selected from among 14 ports that exhibited container-handling capability (referred to as P1, P2, P3, P4, P5, P6, P7, P8, P9, P10, P11, P12, P13, and P14 for the sake of anonymity). By considering the studies in the literature, the dock length, number of cranes (total number of gantry cranes and mobile cranes), depth, and storage spaces were considered to be inputs for performing the efficiency analysis, and the number of handled containers was used as the output. In the study that benefited from the output-oriented CCR model, the analysis was performed using the Frontier Analyst package program, and the results are presented in Table 2.

According to Table 2, among the 14 container ports, three containers (P6, P8, and P9) were efficient while the efficiency values of the remaining 11 ports (P1, P2, P3, $\mathrm{P} 4, \mathrm{P} 5, \mathrm{P} 7, \mathrm{P} 10, \mathrm{P} 11, \mathrm{P} 12, \mathrm{P} 13$, and P14) were lower than 1.000. It was observed that P1 was the port with the lowest efficiency of 0.0885 and that $\mathrm{P} 1$ had to consider $\mathrm{P} 8$ as a reference to ensure efficiency. Consequently, it was decided that the service design application should be made at P1 and that P8, which P1 considered to be a reference, should be considered to be the first rival and P13, which is closely located to P1, should be considered to be the second rival.

Table 2: The Results of Efficiency Analysis

\begin{tabular}{|c|c|c|c|c|c|c|c|}
\hline Port & CRS Eff. & CRS Ref. Set & CRS Ref. Num. & Port & CRS & CRS Ref. Set & CRS Ref. Num. \\
\hline P1 & 0,0885 & P8 & & P8 & 1,0000 & P8 & 9 \\
\hline P2 & 0,4567 & $\mathrm{P} 6$ and P8 & & P9 & 1,0000 & P9 & 1 \\
\hline P3 & 0,6529 & P6 & & P10 & 0,6241 & $\mathrm{P} 6$ and $\mathrm{P} 8$ & \\
\hline P4 & 0,5173 & $\mathrm{P} 6$ and $\mathrm{P} 8$ & & P11 & 0,6976 & P6 & \\
\hline P5 & 0,4163 & P6 and P8 & & P12 & 0,3145 & P6 & \\
\hline P6 & 1,0000 & P6 & 10 & P13 & 0,1902 & P6 & \\
\hline P7 & 0,3809 & P6 and P8 & & P14 & 0,3121 & $\mathrm{P} 6$ and $\mathrm{P} 8$ & \\
\hline
\end{tabular}

Average $=0,5465$ 


\subsection{Testing The Validity and Reliability of The Port Service Quality Scale}

Because the diverse locations of the port's customers made it difficult to conduct face-to-face interviews in terms of time and costs, the scale prepared by Thai (2008), which is widely accepted in literature for improving the service quality of maritime transport, was used to determine the customer requirements. Before beginning to create the house of quality, the validity and reliability of the scale in question had to be verified. In this context, the data obtained from the questionnaire forms were tested using the SPSS and AMOS 20 package programs, and Cronbach's alpha value was estimated to be 0.971 , indicating the high reliability of the scale. Further, the criterion of image was eliminated from the analysis because it adversely affected the validity of the CFA. The last version of the customer requirements scale is presented in Table 3.

Using CFA, the fit indices of RMSEA, AGFI, CFI, GFI, $\mathrm{NFI}, \mathrm{SRMR}$, and X2/df were observed to be $0.066,0.857$, $0.951,0.888,0.920,0.030$, and 2.471 , respectively. The fit indices that were obtained were within acceptable limits. It was also observed that R3 and $\mathrm{O} 6$ had a factor weight of 6.675 and 0.696 , respectively, while other variables had factor weights varying between 0.754 and 0.850 .

\subsection{Determining the Priorities and Weights of Customer Requirements}

In this phase, the objective was to define the requirements of the port's customers and to identify their importance ratings. The scale, developed by Thai (2008) and comprising 5 main and 23 sub-criteria, was used for collecting the required data. The collected data were used to create the pairwise comparison matrices that formed the very basis of the FAHP method. While creating these matrices, the consistency rates of the matrices that were initially formed in the AHP form were calculated; further, after the matrices were observed to be consistent, they were converted to the FAHP form using triangular fuzzy numbers. The analytic hierarchy process and the matrices that have been organized in the FAHP form are presented in Tables 4, 5, 6, 7, 8, and 9.

Table 3: Customer Requirements

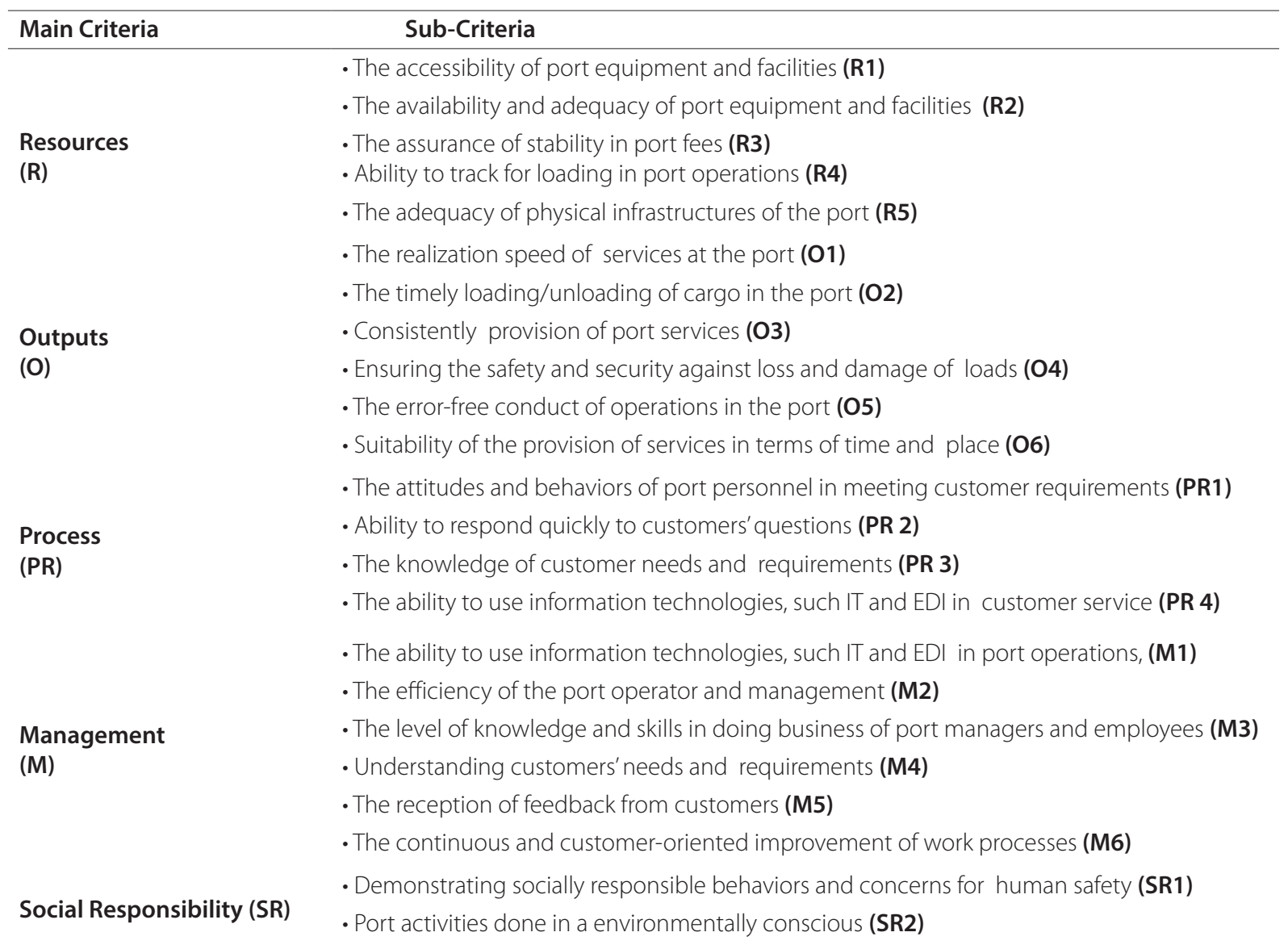


Table 4: Pairwise Comparison Matrix for Main Criteria

\begin{tabular}{|c|c|c|c|c|c|c|c|c|c|c|c|}
\hline & \multicolumn{5}{|c|}{ Pairwise Comparison Matrix of AHP } & & \multicolumn{5}{|c|}{ Pairwise Comparison Matrix of FAHP } \\
\hline & $\mathbf{R}$ & 0 & PR & M & SR & & $\mathbf{R}$ & 0 & PR & M & SR \\
\hline $\mathbf{R}$ & 1 & 3 & 3 & 2 & 3 & $\mathbf{R}$ & $(1,1,1)$ & $(1,3,5)$ & $(1,3,5)$ & $(1,2,3)$ & $(1,3,5)$ \\
\hline 0 & $1 / 3$ & 1 & 2 & 2 & 2 & 0 & $(1 / 5,1 / 3,1)$ & $(1,1,1)$ & $(1,2,3)$ & $(1,2,3)$ & $(1,2,3)$ \\
\hline PR & $1 / 3$ & $1 / 2$ & 1 & 2 & 2 & PR & $(1 / 5,1 / 3,1)$ & $(1 / 3,1 / 2,1)$ & $(1,1,1)$ & $(1,2,3)$ & $(1,2,3)$ \\
\hline$M$ & $1 / 2$ & $1 / 2$ & $1 / 2$ & 1 & 3 & $M$ & $(1 / 3,1 / 2,1)$ & $(1 / 3,1 / 2,1)$ & $(1 / 3,1 / 2,1)$ & $(1,1,1)$ & $(1,3,5)$ \\
\hline SR & $1 / 3$ & $1 / 2$ & $1 / 2$ & $1 / 3$ & 1 & SR & $(1 / 5,1 / 3,1)$ & $(1 / 3,1 / 2,1)$ & $(1 / 3,1 / 2,1)$ & $(1 / 5,1 / 3,1)$ & $(1,1,1)$ \\
\hline
\end{tabular}

Table 5: Pairwise Comparison Matrix for Sub-criteria of Resources

\begin{tabular}{|c|c|c|c|c|c|c|c|c|c|c|c|}
\hline \multicolumn{6}{|c|}{ Pairwise Comparison Matrix of AHP } & \multicolumn{6}{|c|}{ Pairwise Comparison Matrix of FAHP } \\
\hline & R1 & $\mathrm{R} 2$ & R3 & R4 & R5 & & R1 & R2 & R3 & R4 & R5 \\
\hline R1 & 1 & 2 & 2 & 1 & 2 & R1 & $(1,1,1)$ & $(1,2,3)$ & $(1,2,3)$ & $(1,1,3)$ & $(1,2,3)$ \\
\hline R2 & $1 / 2$ & 1 & 2 & 2 & 2 & R2 & $(1 / 3,1 / 2,1)$ & $(1,1,1)$ & $(1,2,3)$ & $(1,2,3)$ & $(1,2,3)$ \\
\hline R3 & $1 / 2$ & $1 / 2$ & 1 & 2 & 2 & R3 & $(1 / 3,1 / 2,1)$ & $(1 / 3,1 / 2,1)$ & $(1,1,1)$ & $(1,2,3)$ & $(1,2,3)$ \\
\hline R4 & 1 & $1 / 2$ & $1 / 2$ & 1 & 2 & R4 & $(1 / 3,1,1)$ & $(1 / 3,1 / 2,1)$ & $(1 / 3,1 / 2,1)$ & $(1,1,1)$ & $(1,2,3)$ \\
\hline R5 & $1 / 2$ & $1 / 2$ & $1 / 2$ & $1 / 2$ & 1 & R5 & $(1 / 3,1 / 2,1)$ & $(1 / 3,1 / 2,1)$ & $(1 / 3,1 / 2,1)$ & $(1 / 3,1 / 2,1)$ & $(1,1,1)$ \\
\hline
\end{tabular}

Table 6: Pairwise Comparison Matrix for Sub-criteria of Outputs

\begin{tabular}{|c|c|c|c|c|c|c|c|c|c|c|c|c|}
\hline \multicolumn{7}{|c|}{ Pairwise Comparison Matrix of AHP } & \multicolumn{6}{|c|}{ Pairwise Comparison Matrix of FAHP } \\
\hline & 01 & 02 & 03 & 04 & 05 & 06 & & 01 & $\mathrm{O} 2$ & 03 & 04 & 05 \\
\hline 01 & 1 & 1 & 2 & 1 & 1 & 2 & 01 & $(1,1,1)$ & $(1,1,3)$ & $(1,2,3)$ & $(1,1,3)$ & $(1,1,3)$ \\
\hline 02 & 1 & 1 & 2 & 2 & 2 & 2 & 02 & $(1 / 3,1,1)$ & $(1,1,1)$ & $(1,2,3)$ & $(1,2,3)$ & $(1,2,3)$ \\
\hline $\mathbf{0 3}$ & $1 / 2$ & $1 / 2$ & 1 & 2 & 2 & 2 & 03 & $(1 / 3,1 / 2,1)$ & $(1 / 3,1 / 2,1)$ & $(1,1,1)$ & $(1,2,3)$ & $(1,2,3)$ \\
\hline 04 & 1 & $1 / 2$ & $1 / 2$ & 1 & 2 & 3 & 04 & $(1 / 3,1,1)$ & $(1 / 3,1 / 2,1)$ & $(1 / 3,1 / 2,1)$ & $(1,1,1)$ & $(1,2,3)$ \\
\hline 05 & 1 & $1 / 2$ & $1 / 2$ & $1 / 2$ & 1 & 2 & 05 & $(1 / 3,1,1)$ & $(1 / 3,1 / 2,1)$ & $(1 / 3,1 / 2,1)$ & $(1 / 3,1 / 2,1)$ & $(1,1,1)$ \\
\hline 06 & $1 / 2$ & $1 / 2$ & $1 / 2$ & $1 / 3$ & $1 / 2$ & 1 & 06 & $(1 / 3,1 / 2,1)$ & $(1 / 3,1 / 2,1)$ & $(1 / 3,1 / 2,1)$ & $(1 / 5,1 / 3,1)$ & $(1 / 3,1 / 2,1)$ \\
\hline
\end{tabular}

Table 7: Pairwise Comparison Matrix for Sub-criteria of Process

\begin{tabular}{|c|c|c|c|c|c|c|c|c|c|}
\hline \multicolumn{5}{|c|}{ Pairwise Comparison Matrix of AHP } & \multicolumn{5}{|c|}{ Pairwise Comparison Matrix of FAHP } \\
\hline & PR1 & PR2 & PR3 & PR4 & & PR1 & PR2 & PR3 & PR4 \\
\hline PR1 & 1 & 1 & 1 & 2 & PR1 & $(1,1,1)$ & $(1,1,3)$ & $(1,1,3)$ & $(1,2,3)$ \\
\hline PR2 & 1 & 1 & 1 & 1 & PR2 & $(1 / 3,1,1)$ & $(1,1,1)$ & $(1,1,3)$ & $(1,1,3)$ \\
\hline PR3 & 1 & 1 & 1 & 2 & PR3 & $(1 / 3,1,1)$ & $(1 / 3,1,1)$ & $(1,1,1)$ & $(1,2,3)$ \\
\hline PR4 & $1 / 2$ & 1 & $1 / 2$ & 1 & PR4 & $(1 / 3,1 / 2,1)$ & $(1 / 3,1,1)$ & $(1 / 3,1 / 2,1)$ & $(1,1,1)$ \\
\hline
\end{tabular}


Table 8: Pairwise Comparison Matrix for Sub-criteria of Management

\begin{tabular}{|c|c|c|c|c|c|c|}
\hline & \multicolumn{6}{|c|}{ Pairwise Comparison Matrix of AHP } \\
\hline & M1 & M2 & M3 & M4 & M5 & M6 \\
\hline M1 & 1 & 1 & 2 & 2 & 2 & 2 \\
\hline M2 & 1 & 1 & 2 & 1 & 2 & 2 \\
\hline M3 & $1 / 2$ & $1 / 2$ & 1 & 2 & 1 & 2 \\
\hline M4 & $1 / 2$ & 1 & $1 / 2$ & 1 & 2 & 2 \\
\hline M5 & $1 / 2$ & $1 / 2$ & 1 & $1 / 2$ & 1 & 1 \\
\hline \multirow[t]{3}{*}{ M6 } & $1 / 2$ & $1 / 2$ & $1 / 2$ & $1 / 2$ & 1 & 1 \\
\hline & \multicolumn{6}{|c|}{ Pairwise Comparison Matrix of FAHP } \\
\hline & M1 & M2 & M3 & M4 & M5 & M6 \\
\hline M1 & $(1,1,1)$ & $(1,1,3)$ & $(1,2,3)$ & $(1,2,3)$ & $(1,2,3)$ & $(1,2,3)$ \\
\hline M2 & $(1 / 3,1,1)$ & $(1,1,1)$ & $(1,2,3)$ & $(1,1,3)$ & $(1,2,3)$ & $(1,2,3)$ \\
\hline M3 & $(1 / 3,1 / 2,1)$ & $(1 / 3,1 / 2,1)$ & $(1,1,1)$ & $(1,2,3)$ & $(1,1,3)$ & $(1,2,3)$ \\
\hline M4 & $(1 / 3,1 / 2,1)$ & $(1 / 3,1,1)$ & $(1 / 3,1 / 2,1)$ & $(1,1,1)$ & $(1,2,3)$ & $(1,2,3)$ \\
\hline M5 & $(1 / 3,1 / 2,1)$ & $(1 / 3,1 / 2,1)$ & $(1 / 3,1,1)$ & $(1 / 3,1 / 2,1)$ & $(1,1,1)$ & $(1,1,3)$ \\
\hline M6 & $(1 / 3,1 / 2,1)$ & $(1 / 3,1 / 2,1)$ & $(1 / 3,1 / 2,1)$ & $(1 / 3,1 / 2,1)$ & $(1 / 3,1,1)$ & $(1,1,1)$ \\
\hline
\end{tabular}

Table 9: Pairwise Comparison Matrix for Sub- criteria of Social Responsibility

\begin{tabular}{|c|c|c|c|c|c|}
\hline \multicolumn{3}{|c|}{ Pairwise Comparison Matrix of AHP } & \multicolumn{3}{|c|}{ Pairwise Comparison Matrix of FAHP } \\
\hline & SR1 & SR2 & & SR1 & SR2 \\
\hline SR1 & 1 & 1 & SR1 & $(1,1,1)$ & $(1,1,3)$ \\
\hline SR2 & 1 & 1 & SR2 & $(1 / 3,1,1)$ & $(1,1,1)$ \\
\hline
\end{tabular}

The consistency rates that were calculated using both Excel and the Super Decisions 2.8 package program are presented in Table 10. The consistency rates of higher than 0.1 indicated that the matrices were consistent.

Table 10: The Consistency Rates of Pairwise Comparison Matrix

\begin{tabular}{lcc}
\hline $\begin{array}{l}\text { Main } \\
\text { Criteria }\end{array}$ & $\begin{array}{c}\text { Solution of } \\
\text { Excel }\end{array}$ & $\begin{array}{c}\text { Solution of Super } \\
\text { Decisions }\end{array}$ \\
\hline R & 0,0719 & 0,0703 \\
$\mathbf{O}$ & 0,0668 & 0,0661 \\
PR & 0,0537 & 0,0536 \\
M & 0,0227 & 0,0227 \\
SR & 0,0370 & 0,0353 \\
\hline
\end{tabular}

After evaluating the matrices, the fuzzy matrices were created for the relevant criteria and sub-criteria using triangular fuzzy numbers. Further, Chang's order analysis method was employed to determine the importance ratings and weights of the criteria, and the observations are presented in Table 11.
According to Table 11, resources are considered to be the most important criterion among the main criteria. It was followed by the outputs, processes, management, and social responsibility criteria. The most important sub-criteria are the "accessibility of port equipment and facilities", "availability and adequacy of port equipment and facilities," and "ensuring stability in port fees."

\subsection{Port service design with fuzzy quality function deployment}

After the importance ratings of the customer requirements are determined using the FAHP, the planning matrix that is located to the right of the house of quality should be created. The planning matrix contains columns denoting the status of satisfaction of the customer requirements for $\mathrm{P} 1$ and its rivals, $\mathrm{P} 8$ and $\mathrm{P} 13$, their target values, improvement rates, points of sale, raw weights, and normalized raw and relative weights. After this stage, the technical requirements that were required for satisfying the requirements of each customer were identified using the quality team. Further, 23 customer requirements and 26 technical requirements on which the quality team agreed are presented in Table 12. 
Table 11: Weight of Criteria

\begin{tabular}{|c|c|c|c|c|}
\hline Main Criteria & Sub-Criteria & Local Weight & Global Weight & Ranking \\
\hline \multirow{5}{*}{$\begin{array}{l}R \\
(0,281)\end{array}$} & $\mathrm{R} 1$ & 0,248 & 0,070 & 1 \\
\hline & $\mathrm{R} 2$ & 0,240 & 0,067 & 2 \\
\hline & R3 & 0,211 & 0,059 & 3 \\
\hline & R4 & 0,180 & 0,051 & 6 \\
\hline & $\mathrm{R} 5$ & 0,121 & 0,034 & 13 \\
\hline \multirow{6}{*}{$\begin{array}{l}0 \\
(0,222)\end{array}$} & $\mathrm{O} 1$ & 0,188 & 0,042 & 9 \\
\hline & $\mathrm{O} 2$ & 0,205 & 0,045 & 8 \\
\hline & $\mathrm{O} 3$ & 0,182 & 0,040 & 11 \\
\hline & $\mathrm{O4}$ & 0,182 & 0,040 & 11 \\
\hline & $\mathrm{O5}$ & 0,141 & 0,031 & 15 \\
\hline & O6 & 0,102 & 0,023 & 17 \\
\hline \multirow{4}{*}{$\begin{array}{l}\text { PR } \\
(0,194)\end{array}$} & PR1 & 0,284 & 0,055 & 5 \\
\hline & PR2 & 0,256 & 0,050 & 7 \\
\hline & PR3 & 0,284 & 0,055 & 5 \\
\hline & PR4 & 0,176 & 0,034 & 13 \\
\hline \multirow{6}{*}{$\begin{array}{l}M \\
(0,191)\end{array}$} & M1 & 0,213 & 0,041 & 10 \\
\hline & $M 2$ & 0,202 & 0,038 & 12 \\
\hline & M3 & 0,178 & 0,034 & 13 \\
\hline & M4 & 0,171 & 0,033 & 14 \\
\hline & M5 & 0,132 & 0,025 & 16 \\
\hline & M6 & 0,105 & 0,020 & 18 \\
\hline SR & SR1 & 0,500 & 0,056 & 4 \\
\hline$(0,112)$ & SR2 & 0,500 & 0,056 & 4 \\
\hline
\end{tabular}

Further, the relation matrix was created for connecting the customer requirements with technical requirements, and the priority status of technical requirements was determined. After the raw and relative importance weights of technical requirements were calculated, the present status of the ports in terms of technical requirements was evaluated, and the target values were specified. Finally, the correlation matrix was created, and positive or negative relation levels were identified among the technical requirements. All parts of the house of quality that have been described so far are presented in Figure 5.

Table 12: Technical Requirements

\begin{tabular}{|c|c|c|}
\hline \multicolumn{2}{|c|}{ Customer Requirements } & \multirow{2}{*}{$\begin{array}{l}\text { Technical Requirements } \\
\text { Connection with transport modes of port (Highway, airway, railway, waterway and pipelines) (TR1) }\end{array}$} \\
\hline \multirow{6}{*}{$\mathbf{R}$} & R1 & \\
\hline & $\mathrm{R} 2$ & Standards-compliant facilities and equipment (TR2) \\
\hline & D2 & Ceiling and floor price application in port fees (TR3) \\
\hline & R3 & Connecting to contract of port fees (TR4) \\
\hline & R4 & Automation system suitable to load diversity and adequacy of system (TR5) \\
\hline & R5 & Dock structure and number in port (TR6) \\
\hline \multirow{8}{*}{0} & & Competence and sufficiency of employees (TR7) \\
\hline & 01 & Information and processing speed between units (TR8) \\
\hline & 02 & Planning of load handling operations (Docks, equipment, workforce planning) (TR9) \\
\hline & 03 & Standardization of services (Regulating of service standards) (TR10) \\
\hline & & An effective security system (TR11) \\
\hline & 04 & Insurance system (TR12) \\
\hline & 05 & An effective inspection and control system (TR13) \\
\hline & 06 & 24 hours service (TR14) \\
\hline \multirow{5}{*}{ PR } & PD1 & Training in customer relations of employees (TR15) \\
\hline & PKI & Internal customer satisfaction (TR16) \\
\hline & PR2 & Accessibility to authorized personnel (TR17) \\
\hline & PR3 & $\begin{array}{l}\text { Customer relationship management (Collection of customer information, consideration of } \\
\text { complaints and suggestions) (TR18) }\end{array}$ \\
\hline & PR4 & An effective information technology infrastructure (TR19) \\
\hline \multirow{6}{*}{ M } & M1 & An effective information technology infrastructure (TR19) \\
\hline & M2 & Efficient use of land, lobar, tools, etc. resources of port (TR20) \\
\hline & M3 & All managers and employees have the necessary experience and professional qualifications (TR21) \\
\hline & M4 & The activities carried out with the customers (TR22) \\
\hline & M5 & Service quality and satisfaction surveys (TR23) \\
\hline & M6 & Continuous improvement and total quality management (TR24) \\
\hline \multirow{2}{*}{ SR } & SR1 & Corporate social responsibility activities (TR25) \\
\hline & SR2 & Green Port (Eco Port) certificate and ISO 14001 environmental management systems (TR26) \\
\hline
\end{tabular}




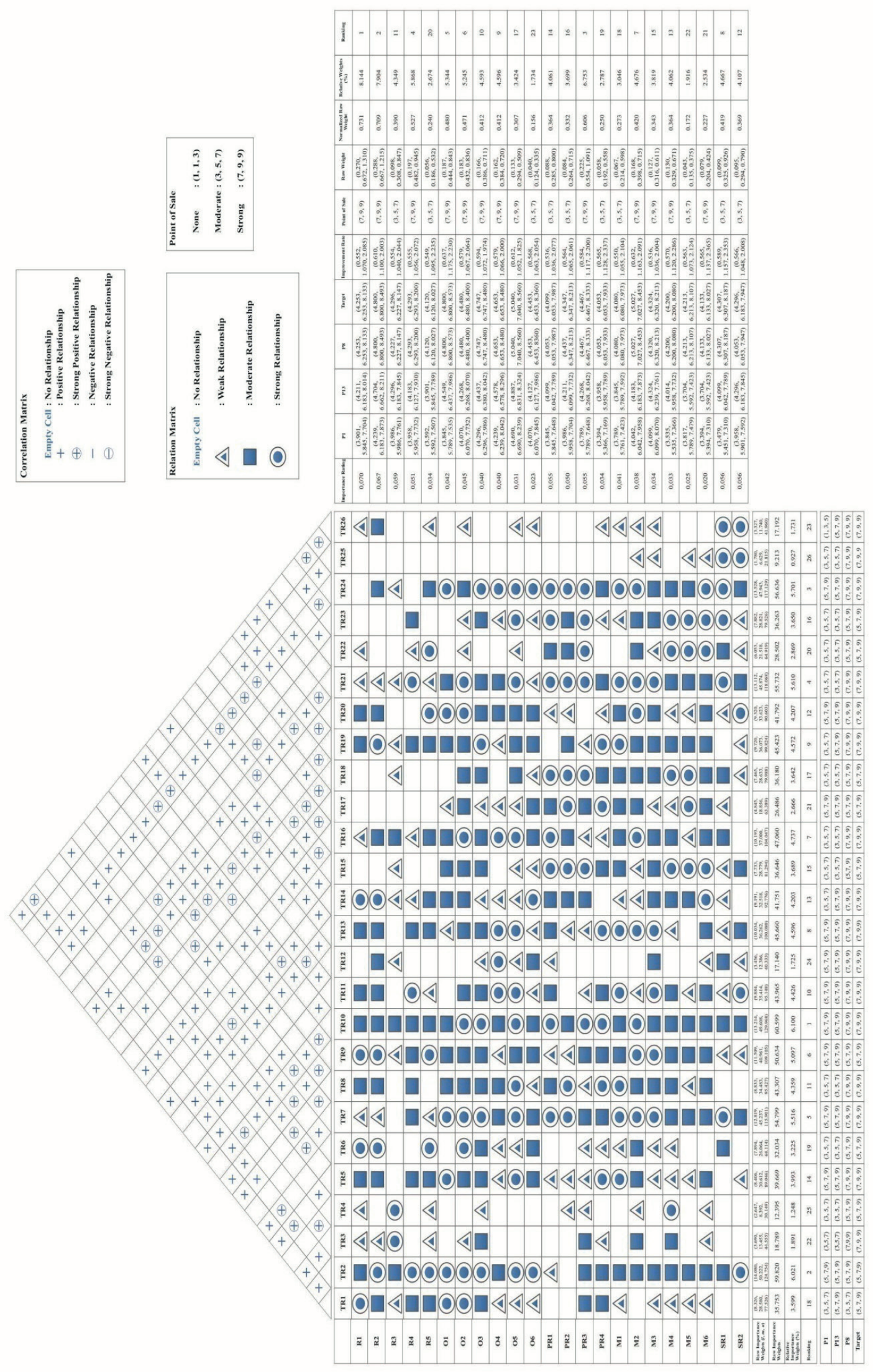

Figure 5: House of Quality 
According to Figure 5, the accessibility of port equipment and facilities, the availability and adequacy of port equipment and facilities, and the assurance of stability in port fees are the customer requirements with the highest level of importance while the continuous and customer-oriented improvement of work processes is the customer requirement with the lowest level of importance. According to the planning matrix, the initial three most important requirements that would ensure customer satisfaction are the accessibility of port equipment and facilities, the availability and adequacy of port equipment and facilities, and the knowledge of customer requirements while the requirements with the lowest level of importance are listed as suitability of the provision of services in terms of time and place, the reception of feedback from customers, and the continuous and customer-oriented improvement of work processes. Based on the planning matrix, P13 exhibited a low performance with respect to the reception of feedback from customers, and the $\mathrm{P} 13$ and $\mathrm{P} 8$ ports performed better than the $\mathrm{P} 1$ port in terms of all the other requirements.

The observations have demonstrated that P1 failed to satisfy the customer requirements. The most important reasons for this failure were observed to be the shortcomings regarding the accessibility of port equipment and facilities, the availability and adequacy of port equipment and facilities, and the knowledge of customer requirements; further, the most important requirements that would ensure customer satisfaction were identified to be the standardization of services, standard-compliant facilities and equipment, and continuous improvement and total quality management. In accordance with these observations, the improvement rates and target values were determined for $\mathrm{P} 1$, and $\mathrm{P} 1$ was also evaluated in terms of each technical requirement. When compared to $P 13$ and P8, P1 was lower than the target values in all technical requirements except for the standards-compliant facilities and equipment, the planning of cargo handling operations, and the availability of authorized personnel.

The relation matrix of the house of quality in Figure 5 indicates that the technical requirement that was most frequently associated with customer requirements was the error-free conduct of operations in the port. This technical requirement was followed by the timely loading/ unloading of cargo in the port, the attitudes and behaviors of port personnel in meeting customer requirements, the ability to use information technologies, such IT and EDI, in port operations, and the efficiency of the port operator and management. In the technical evaluation matrix of the house of quality, each port among P1, P13, and P8 was separately evaluated against each technical requirement, and the target values were identified by comparing the current status of $\mathrm{P} 1$ with that of $\mathrm{P} 13$ and $\mathrm{P} 8$. In this context, $\mathrm{P} 1$ was found to achieve target values for the technical requirements for standards-compliant facilities and equipment, the planning of cargo handling operations, and the availability of authorized personnel but failed in terms of all other technical requirements. According to the correlation matrix that formed the final stage of the house of quality, positive and strongly positive relations were identified among the technical requirements, and it was concluded that the technical requirements supported each other.

\section{CONCLUSION}

The maritime transport sector should be treated from a holistic perspective to elicit its benefits, particularly because a significant proportion of global trade is performed through it. Because the port operators form the backbone of the maritime transport and, at the same time, are major players in this sector, the factors, such as adequacy, quality, effectiveness, and the efficiency of the services that are provided by them, are becoming increasingly important. Ineffective and inefficient port activities may lead to increased costs, loss of competitive edge, and customer dissatisfaction. The ports operating in national and international markets must adapt to the changes in economic, social, and cultural life and improve the quality of their services to survive. In this context, the port operators should consider the service design and presentation that considers the customer requirements to be essential.

To support the port operators for change and self-improvement, this study has developed a customer-oriented service design proposal for the inefficient port $\mathrm{P} 1$. The observations indicated that the port in question performed poorly in satisfying the customer requirements and achieving the target values when compared to its rivals. To provide quality services, P1 should make improvements in terms of its equipment, facilities, technological infrastructure, handling operations, and skilled personnel and comply with the green port standards for minimizing the environmental and noise pollution, harmful gas emissions, accidents, and other such adversities that may emerge during operations.

Further, the limitations of this study should be considered to accurately construe its results in a beneficial manner. The first limitation is that a perceived service 
quality scale that is extensively accepted in national and international literature has been used to identify the customer requirements; further, the statements in this scale were considered to be customer requirements. Another limitation is that only the most important technical requirements were included in the study. Indeed, the inclusion of all the technical requirements would result in large matrices, further complicating the decision-making processes. The third limitation is that part of the data that were used in the methods employed by this study relied on the subjective opinions of customers and experts. Therefore, it should be remembered that another study in another port may yield different results depending on the selected experts and customers. The final limitation is that this study was performed in a port having the lowest efficiency rating because of cost and time restrictions; further, the results cannot be generalized for other port operators.

In this study, the requirements of the port customers was determined by using Thai (2008)'s service quality scale. However, consumer requirements can be determined by other methods. Also, a consumer requirements scale can be developed instead of the using a preset scale. Further, the port service should be designed by using all the stages of QFD. Besides numerous service design techniques such as Failure Mode and Effects Analysis (FMEA), Service Mapping (SM) and Creative Problem Solving (CPS) including FQFD can be used in the further studies. 


\section{References}

Akbaba, A., 2005. The quality function deployment (QFD) approach in customer focused service production: An application study for hospitality industry", Anatolia, Journal of tourism Research, 16,1, 59-81.

Baird, A.J., 1995. Privatisation of trust ports in The United Kingdom: Review and analysis of the first sales. Transport Policy. 2, 2, 135-143.

Bakirci, F., 2006. Üretimde etkinlik ve verimlilik ölçümü, veri zarflama analizi teori ve uygulama. İstanbul: Atlas Yayınları, 1. Baskı.

Becker, A., Inoue, S., Fischer, M., Schwegler, B., 2011. Considering climate change: A survey of global seaport administrators. CIFE Working Paper WP128, Stanford University, 1-69.

Bevilacqua, M., Ciarapica, F.E., Marchhetti, B., 2012. Development and test of a new fuzzy- QFD approach for characterizing customers rating of extra virgin olive oil. Food Quality and Preference. 24, 75- 84.

Bottani, E., Rizzi, A., 2006. Strategic management of logistics service: A fuzzy QFD approach. International Journal of Production Economics. 103, 585-599.

Branch, A. E., 1986. Elements of port operation and management. London, Chapman and Hall.

Buyukozkan, G., Feyzioglu, O., Ruan, D., 2007. Fuzzy group decision-making to multiple preference formats in Quality Function Deployment. Computers in Industry. 58, 392- 402.

Byrne, B.M., 2010. Structural equation modeling with AMOS, basic concepts, applications and programming. Taylor Francis Group, 2. Edition, LLC.

Chamzini, A.Y., Yakhchali, S.H., 2012. Tunnel boring machine (TBM) selection using fuzzy multicriteria decision making methods. Tunnelling and Underground Space Technology, 30, 194-204.

Chan, F.T.S., Kumar, N., 2007. Global supplier development considering risk factors using fuzzy extended ahp-based approach. Omega The International Journal of Management Science. 35, 417-431.

Chang, D.Y., 1996. Applications of the extent analysis method on fuzzy AHP. European Journal of Operational Research. 95, 649-655.

Charnes, A., Cooper, W.W., Lewin, A.Y., Seiford, L.M., 1994. Data envelopment analysis: Theory, methodology and application. Springer Science +Business Media, LLC.

Cooper, W.W., Li, S., Seiford, L.M., Tone, K., Thrall, R.M., Zhu, J., 2001. Sensitivity and stability analysis in DEA: Some recent developments. Journal of Productivity Analysis. 15, 217246.

Cooper, W.W., Seiford, L., M., Tone, K., 2007. Data envelopment analysis, A comprehensive text with models, applications, references and DEA-solver software. Springer Science, Business Media, LLC. Second Edition.
Cooper, W.W., Seiford, L.M., Zhu, J., 2004. Handbook on data envelopment analysis, Kluwer Academic Publishers.

Costa, A.I.A., Dekker, M., Jongen, W.M.F., 2001. Quality function deployment in the food industry: A review. Trend in Food Science \& Technology. 11, 306-314.

Day, R.G., 1998. Quality function deployment: Integration of a company with its customers. ASQC Quality Press Milwaukee, Wisconsin.

Deng, H., 1999. Multicriteria analysis with fuzzy pairwise comparison. International Journal of Approximate Reasoning. 21, 215-231.

Ding, J. F., 2009. Applying fuzzy quality function deployment (QFD) to identify solutions of service delivery system for port of Kaohsiung, Qual Quant, 43, 553-570.

Duru, O., Huang, S. T., Bulut, E., 2013. Multi-layer quality function deployment (QFD) approach for improving the compromised quality satisfaction under the agency problem: A 3D QFD design for the asset selection problem in the shipping industry, Qual Quant, 47, 2259-2280.

Dyson, R.G., Allen, R., Camanho, A.S., Podinovski, V.V., Sarrico, C.S., Shale, E.A., 2001. Pitfalls and protocols in DEA. European Journal of Operational

Ertugrul, I., Karakasoglu, N., 2008. Comparison of fuzzy AHP and fuzzy TOPSIS methods for facility location selection. Int. J. Adv. Manuf Technol. 39, 783-795.

Esmer, S., Cetin, C.K., 2016. Liman işletme yönetimi, in: Güldem Cerit, Ali Deveci ve Soner Esmer (eds.), Denizcilik İşletmeleri Yönetimi. Beta Basım A.Ş., İstanbul: 2.Basım, 377-416.

Ficalora, J.P., Cohen, L., 2010. Quality function deployment and sIX sıgma: A QFD Handbook, Pearson Education. Inc, Second Edition, Boston.

Golany, B., Roll, Y., 1989. An application procedure for DEA. Omega. 17, 3, 237-250.

Han, S.B., Chen, S.K., Ebrahimpour, M., Sodhi, M., 2001. A conceptual QFD planning model. International Journal of Quality \& Reliability Management. 18, 8, 796-812.

Hsu, W. K. K., 2013. Improving the service operations of container terminals, The International Journal of Logistics Management, 24, 1, 101-116.

Huang, C.C., Chu, P.Y., Chiang, Y.H., 2008. A fuzzy AHP application in government-sponsored R\&D project selection. Omega. 36, 6, 1038-1052.

Huang, S. T., Bulut, E., Duru, O., 2015. Service quality assessment in liner shipping industry: an empirical study on Asian shipping case, Int. J. Shipping and Transport Logistics, 7, 2, 221-242.

Huang, S. T., Bulut, E., Duru, O., 2019. Service quality evaluation of international freight forwarders: an empirical research in East Asia, Journal of Shipping and Trade, 4, 14,1-16. 
Jeong, M., Oh, H., 1998. Quality function deployment: An extended framework for service quality and customer satisfaction in the hospitality industry, hospitality industry. Hospitality Management. 17, 375-390.

Kahraman, C., Cebeci, U., Ruan, D., 2004. Multi-attribute comparison of catering service companies using fuzzy AHP:The case of Turkey. Int. J. Production Economics. 87, 171-184.

Khoo, L., P., Ho, N.C., 1996. Framework of a fuzzy quality function deployment system. Int. J. Prod. Res. 34, 2, 299-311.

Liu, H.T., 2009. The extension of fuzzy QFD: From product planning to part deployment. Expert Systems With Applications. 36, 11131-11144.

Mangan, J., Lalwani, C., Fynes, B., 2008. Port- Centric Logistics. The International Jounal of Logistics Management. 19, 1, 29- 41.

Nakip, M., 2013. Pazarlamada araştırma teknikleri. Ankara: Seçkin Yayıncılık, 3. Baskı.

Ramanathan, R., 2003. An introduction to data envelopment analysis: A tool for performance measurement, New Delhi: Sage Publications.

Rao, R.V., 2008. Evaluating flexible manufacturing systems using a combined multiple attribute decision making method. International Journal of Production Research. 46, 1, 1975-1989.

Razik, M. A., Tahar, R. M., Hasrulnizzam, W., Mahmood, W., Rozar, N., M., 2015. Integrated Quality Function Deployment (QFD) Model for Dry Bulk Terminal Improvements (DBTI) in Malaysian Ports, Journal of Economics, Business and Management, 3, 4, 413-416.
Schermelleh-Engel, K., Moosbrugger, H., Müller, H., 2003. Evaluating the fit of structural equation models: Tests of significance and descriptive goodness-of-fit measures. Methods of Psychological Research. 8, 2, 23-74.

Tahar, R.M., Hussain, K., 2000. Simulation and analysis fort he Kelang container terminal operations. Logistics Information Management. 13, 1, 14-20.

Thai, V.V., 2008. Service quality in maritime transport: Conceptual model and empirical evidence. Asia Pacific Journal of Marketing and Logistics. 20, 4, 493-518.

TURKLIM, Türkiye Liman İşletmecileri Derneği 2010. Türk Limancilık Sektörü Raporu. 1-182.

UNCTAD, United Nations Conference on Trade and Development 1992, Review of Maritime Transport, available at: http://unctad.org/en/PublicationsLibrary/rmt1992_ en.pdf (accessed 9 May 2016).

Weber, C.A., 1996. A data envelopment analysis approach to measuring vendor performance. Supply Chain Management. 1, 1, 28-39.

World Bank 2007. Port reform toolkit, module 3, alternative port management structures and ownership models. available at: https://ppiaf.org/sites/ppiaf.org/files/documents/toolkits/Portoolkit/Toolkit/pdf/modules/03_TOOLKIT_Module3.pdf (accessed 17 February 2017). 